Retrospective Evaluation

\title{
e Risk Factors for the Occurrence of Insufficient Cement Distribution in the Fractured Area after Percutaneous Vertebroplasty in Osteoporotic Vertebral Compression Fractures
}

Lin-qiang Ye, MD1', De Liang, MM'1 Xiao-bing Jiang, MD',3, Zhen-song Yao, MD',

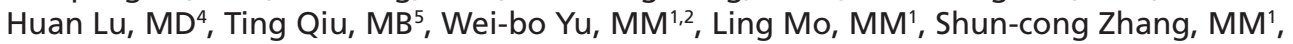
and Da-xiang Jin, MD ${ }^{1}$

From: 'Department of Spinal Surgery, The First Affiliated Hospital of Guangzhou University of Chinese Medicine,

Guangzhou, Guangdong, People's Republic of China; ${ }^{2}$ First School of Clinical Medicine, Guangzhou University of Chinese Medicine, Guangzhou, Guangdong, People's Republic of China; 3Department of Digital Orthopaedics and Biomechanics, Laboratory Affiliated to National Key Discipline of Orthopaedics and Traumatology of Chinese Medicine, Guangzhou University of Chinese Medicine, Guangzhou, Guangdong,

People's Republic of China; ${ }^{4}$ Department of Nephrology, The First Affiliated Hospital of Guangzhou University of Chinese Medicine, Guangzhou, Guangdong, People's Republic of China; 5School of Nursing, Guangzhou University of Chinese Medicine, Guangzhou, Guangdong, People's Republic of China

Address Correspondence: Xiaobing Jiang, MD Department of Spinal Surgery, The First Affiliated Hospital of Guangzhou, University of Chinese Medicine, Airport Road 16, Guangzhou 510405, China E-mail: spinedrjxb@sina.com

De Liang and Lin-qiang Ye contributed equally to this paper. Conflict of interest: The authors gratefully acknowledge support from Projects of The Health Ministry of China (NO.W2012ZTo7, NO.W2014ZT256) and Guangdong Province Medical Science and Technology Research Program (NO.B2014175).

Manuscript received: 12-06-2015 Revised manuscript received: 02-16-2016 Accepted for publication: 02-19-2016

Free full manuscript: www.painphysicianjournal.com
Background: Insufficient cement distribution (ICD) in the fractured area has been advocated to be responsible for unsatisfied pain relief after percutaneous vertebroplasty (PVP) for osteoporotic vertebral compression fractures (OVCFs). However, little is known about risk factors for the occurrence of ICD.

Objective: The present study aimed to identify independent risk factors of the emergence of ICD.

Study Design: A retrospective cohort study.

Setting: Department of spinal surgery, an affiliated hospital of a medical university.

Methods: Patients who underwent PVP for single-level OVCF from January 2012 to September 2014 and met this study's inclusion criteria were retrospectively reviewed. Associations of ICD with co-variates (age, gender, bone mass density with a T-score, amount of injected cement, cement leakage, fracture level, fracture age, fracture severity grade, and location of the fractured area) and the influence of ICD on pain relief were analyzed.

Results: A total of 225 patients were included. ICD was found in $26(11.6 \%)$ patients. Fractured area located in the superior portion of the index vertebra was significantly associated with occurrence of ICD. No further significant associations between the studied co-variates and emergence of ICD were seen in the adjusted analysis. In addition, patients with ICD had significantly higher immediate postoperative visual analog scale scores of back pain compared with those with sufficient cement distribution in the fractured area.

Limitation: Location of the fractured area and cement distribution in the fractured area could not be evaluated quantitatively.

Conclusions: The incidence of ICD is higher in patients with the fractured area located in the superior portion of the index vertebra and ICD might be responsible for unsatisfied pain relief after PVP for OVCFs.

Key words: Percutaneous vertebroplasty, insufficient cement distribution, fractured area, risk factor, osteoporosis, vertebral compression fracture, spine, unsatisfied pain relief, cement augmentation

Pain Physician 2018; 21:E33-E42 


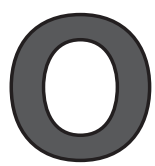

steoporotic vertebral compression fractures (OVCFs) are very common in the elderly, with an estimated 1.4 million new fractures occurring every year worldwide (1). OVCFs may cause pain, limited physical function, decreased quality of life, and increased mortality (2-4). In cases with persistent pain, OVCFs have been traditionally treated with bed rest, analgesics, braces, and physical therapy $(5,6)$. However, such treatments are only partially effective, and about one third of patients have been reported to suffer from persistent pain and progressive functional limitation $(7,8)$.

Since the introduction of percutaneous vertebroplasty (PVP) by Galibert et al in 1987 (9), this minimally invasive therapy has gained popularity as a stabilizing treatment for symptomatic OVCFs that are refractory to conservative management (10). Despite patients typically presented with rapid and durable pain relief and often regaining lost function $(7,11)$, unrelieved pain after PVP has been reported and insufficient cement distribution (ICD) in the unstable fractured area of the index vertebra might explain this observation (12-14). However, few studies are available concerning the reasons why ICD could happen.

Therefore, it seems logical to assume that the identification of the risk factors related to the occurrence of ICD would help to minimize the incidence of ICD, which could ultimately optimize the results of our treatment. Thus, the purpose of this study was to identify independent risk factors for the emergence of ICD following PVP in patients with OVCFs.

\section{Methods}

\section{Patients}

The medical records of patients who underwent PVP for painful vertebral compression fractures between January 2012 and September 2014 at our institution were retrospectively reviewed. Protocol of this study was approved by the ethics committee of our hospital and written informed consent was obtained from each patient. The inclusion criteria were single-level symptomatic OVCF treated with PVP, available preoperative magnetic resonance imaging (MRI) and postoperative computed tomography (CT) scan. The exclusion criteria were non-osteoporotic vertebral compression fractures or compression fractures secondary to other factors, such as pathologic fractures due to metastasis or symptomatic hemangioma; unavailable preoperative MRI and postoperative CT scan; and multiple-level PVP patients.

\section{PVP}

All of PVP procedures were performed by 3 experienced spinal surgeons with standard training in PVP techniques. Patients were carefully positioned in a prone position with an extended posture on a radiolucent operating table. PVP was performed under local anesthesia ( $1 \%$ lidocaine) in all cases. A bilateral transpedicle approach was used for all patients. According to Jensen et al's technique (15), under fluoroscopic C-arm guidance, 11 to 13 gauge bone biopsy needles were inserted parallel to the superior and inferior edges of the pedicle, or in a slightly descending course through the pedicle. The stylet was removed from the trocar when the needle tip was optimally positioned, after which bone cement, which was thicker than a toothpaste-like consistency, was inserted into the vertebral body. The bone cement was prepared by combining polymethylmethacrylate powder with sterile barium sulfate for opacification, followed by the addition of liquid monomer (Tianjin Synthetic Material Research Institute, Tianjin, China). The cement injection process was monitored continuously under C-arm fluoroscope in the lateral plane. Injection was temporarily halted when initial cement leakage, without any discomfort to the patients, was noted and terminated on the reoccurrence of cement leakage or when bone cement reached the posterior quarter of the vertebral body to avoid cement leakage into spinal canal or neural foramina. In general, bone cement was injected until there was a satisfactory distribution judged by the operators. Patients were on enforced bed rest for a few hours and treated with calcium and vitamin D supplements for anti-osteoporosis after PVP.

\section{Data Collection}

Data were collected on age, gender, preoperative and immediate postoperative visual analog scale (VAS) score for back pain, bone mass density (BMD) with a T-score, amount of injected cement, cement leakage, fracture level, fracture age, fracture severity grade, location of the fractured area, and cement distribution in the fractured area. Two independent spinal surgeons were involved in the radiographic evaluation. When there was disagreement between them, a consensus meeting was held.

Age, gender, preoperative and immediate postoperative VAS for back pain, BMD T-score, amount of injected cement, fracture level, and fracture age were recorded in reviewing medical records of the patients. VAS was routinely used to record the degree of back 
pain felt by all patients before surgery and on the second day after surgery. The measures were recoded before analgesic drug therapy. The BMD T-scores were measured using dual-energy $x$-ray absorptiometry (QDR4500, Holigic, Bedford, USA), and L2-L4 vertebra were selected for these measurements. Cement leakage, defined as the presence of any extravertebral cement, was assessed on the postoperative $\mathrm{CT}$ scan of the treated levels. Fracture level of T1-T10, T11-L2, and L3L5 were defined as thoracic, thoracolumbar, and lumbar segments, respectively. Fracture age was defined as the time between the onset of new back pain related to a radiological confirmed fracture and admission into hospital. Fracture severity grade was characterized according to the semiquantitative classification of Genant et al (16), in which the diminished vertebral height was in the severity range from mild to moderate to severe, or $20 \%$ to $25 \%, 26 \%$ to $40 \%$, and more than $40 \%$, respectively, of height reduction. Location of the fractured area was defined as the line-shape area with hypo-intensity in MRI T1-weighted, T2-weighted, shorttau-inversion-recovery sequences and increased density in CT imaging indicating impaction of the fractured area and classified into 3 types including superior, middle, and inferior with the fractured area in the corresponding parts of the index vertebra observed in the sagittal images (Fig. 1). Patients with unclear MRI or extremely irregular fractured area that involved 2 or 3 parts of the index vertebra were also excluded from this study.

For the purpose of this study, patients were divided into those who obtained sufficient cement distribution in the fractured area (Sufficient Group) and those who did not obtain sufficient cement distribution in the fractured area (Insufficient Group). Sufficient cement distribution in the fractured area was defined as cement distribution in more than half of the fractured area observed on postoperative CT scan of the treated levels (Fig. 2). On the contrary, ICD was defined as cement distribution in less than half of the fractured area (Fig. 3).

\section{Statistical Analysis}

Quantitative variables were described using means and standard deviations, whereas frequencies were reported for qualitative variables. Univariate analysis was used to assess clinical outcome of preoperative and immediate postoperative VAS for back pain within and between the 2 groups and risk factors (age, gender, BMD T-score, amount of injected cement, cement leakage, fracture level, fracture age, fracture severity grade, and location of fractured area) associated with the emergence of ICD between the 2 groups. Continuous data were compared using the student $t$ test and Mann-Whitney test or Wilcoxon signed-ranks test when data were non normality or heteroscedasticity, whereas discontinuous data were analyzed using the Chi-squared test or Fisher exact test and Mann-Whitney test when data were ordinal. In addition, a multivariate stepwise logistic regression analysis was performed to identify which independent factors helped to predict the occurrence of ICD, with adjustments made for other potential confounding factors. These statistical tests were 2-tailed and a $P<0.05$ was considered to be significant. Corresponding $95 \%$ confidence limits (Cls) were calculated with confidence interval estimation. Statistical analysis was conducted using SPSS statistical package, version 13.0 (SPSS Inc., Chicago, IL).

\section{Results}

A total of 225 cases were finally included in this study. The associated clinical and radiographic features were described in Table 1. ICD was found in $26(11.6 \%)$ patients. The postoperative back pain score in both groups was significantly lower in comparison to preoperative back pain score $(P<0.001)$. The immediate postoperative VAS for back pain, however, was significantly higher in the Insufficient Group than in the Sufficient Group $(P<0.001)$ while no statistical differences in preoperative VAS for back pain between the 2 groups were identified $(P=0.525)$ (Table 1).

Non-adjusted comparisons using univariate analysis between patients with and without sufficient cement distribution in the fractured area showed that there were no significant differences between the 2 groups regarding age, gender, BMD T-score, amount of injected cement, cement leakage, fracture level, fracture age, and fracture severity grade $(P>0.05)$ except location of the fractured area $(P=0.028)$ (Table 1).

Multivariate stepwise logistic regression analysis also indicated that age, gender, BMD T-score, amount of injected cement, cement leakage, fracture level, fracture age, and fracture severity grade were not significantly associated with the occurrence of ICD $(P>$ $0.05)$. Only location of the fractured area was revealed to be significantly associated with the emergence of ICD $(P=0.040)$. According to dummy variable analysis of the model, patients with the fractured area located in the superior portion of the index vertebra had a 4.8-times $(95 \% \mathrm{Cl} 1.1-21.7, P=0.041)$ higher likelihood for occurrence of ICD than those with the fractured area being in the inferior portion, but no statistical 
Pain Physician: January/February 2018; 21:E33-E42

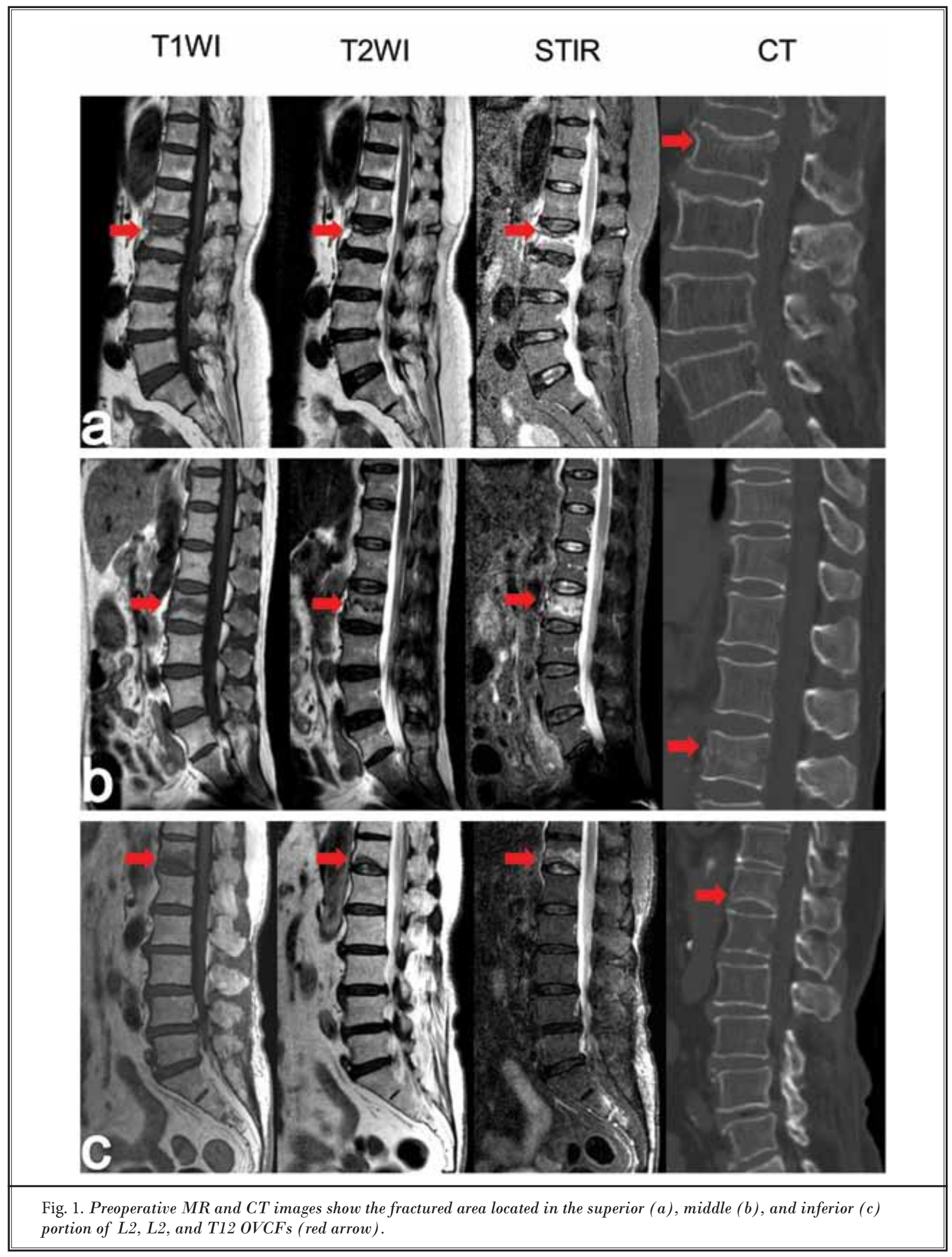


Risk Factors for the Occurrence of Insufficient Cement Distribution

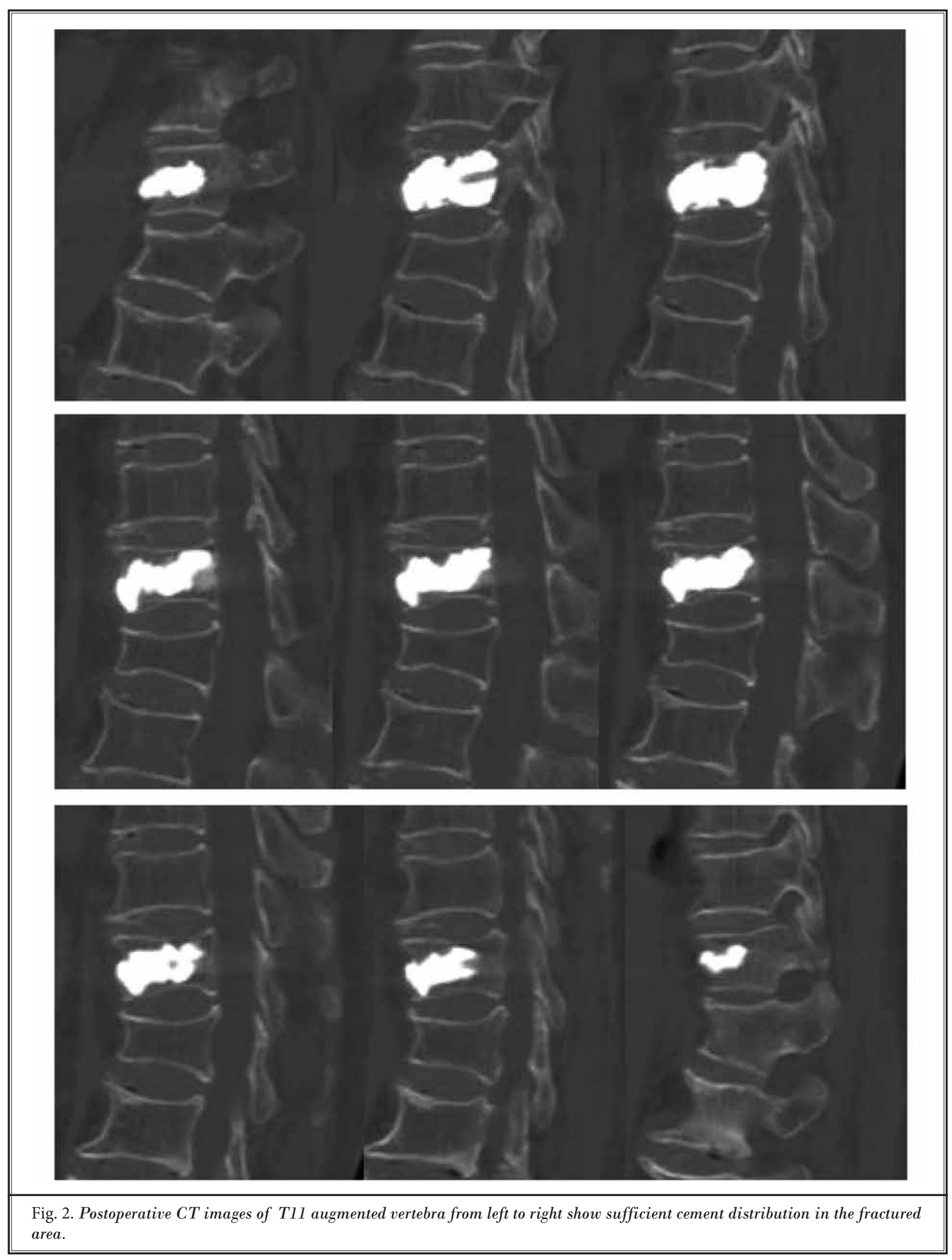


Pain Physician: January/February 2018; 21:E33-E42
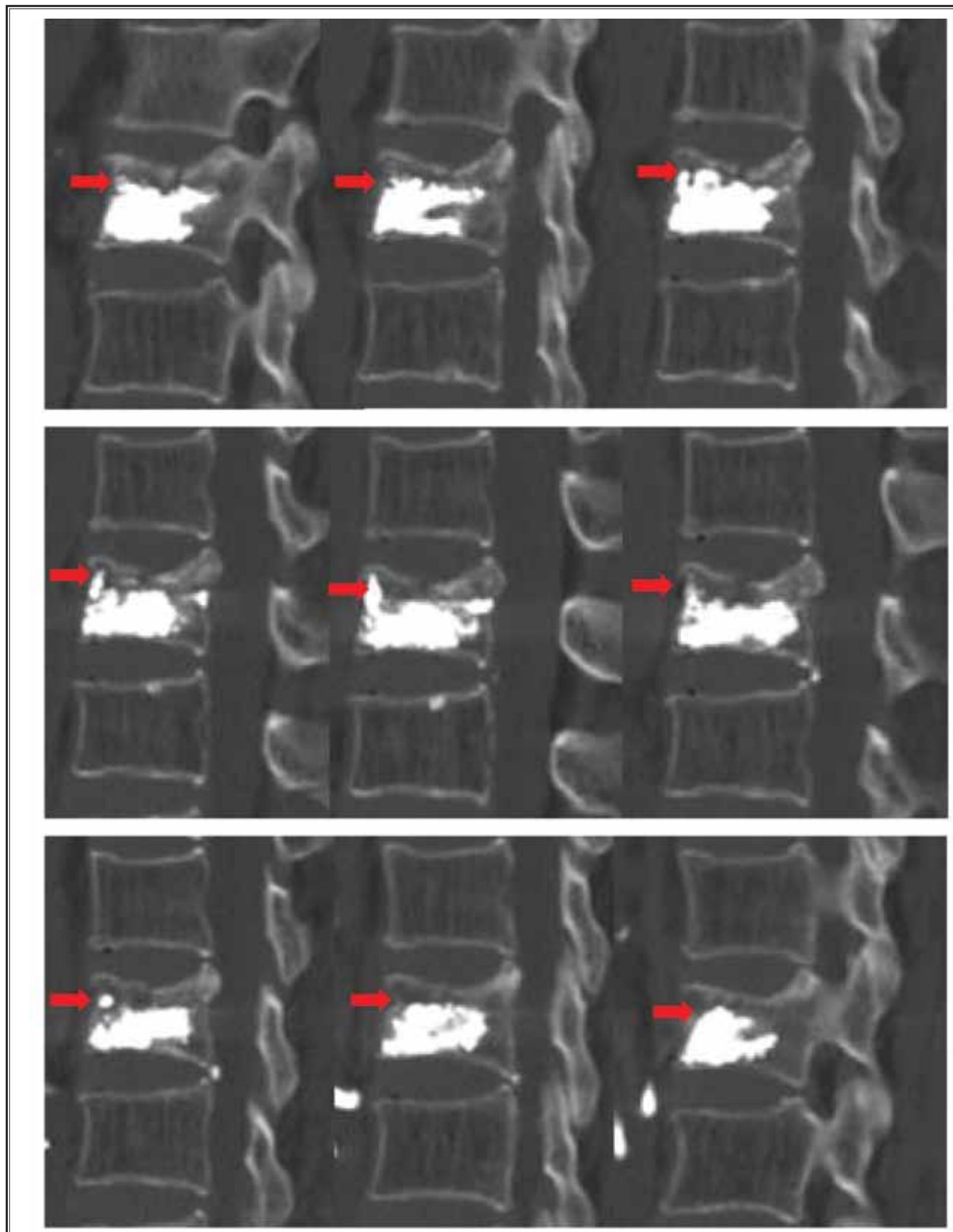

Fig. 3. Postoperative CT images of L2 augmented vertebra from left to right show insufficient cement distribution in the fractured area (red arrow). 
Risk Factors for the Occurrence of Insufficient Cement Distribution

Table 1. Results of univariate analysis for demographic and clinical characteristics of the patients with sufficient and insufficient cement distribution in the fractured area.

\begin{tabular}{|c|c|c|c|c|}
\hline & \multicolumn{2}{|c|}{ Cement distribution in the fractured area } & \multirow{2}{*}{$\begin{array}{c}\text { Total } \\
(n=225)\end{array}$} & \multirow{2}{*}{$\begin{array}{c}\text { Comparison } \\
\text { ( } P \text { value })\end{array}$} \\
\hline & $\begin{array}{c}\text { Insufficient } \\
(\mathrm{n}=26)\end{array}$ & $\begin{array}{l}\text { Sufficient } \\
(\mathrm{n}=199)\end{array}$ & & \\
\hline Age (years) & $73.4 \pm 6.9$ & $73.9 \pm 10.0$ & $73.8 \pm 9.7$ & 0.504 \\
\hline Gender (male/female) & $6 / 20$ & $28 / 171$ & $34 / 191$ & 0.245 \\
\hline BMD (T-score) & $-4.1 \pm 0.8$ & $-4.0 \pm-0.8$ & $-4.0 \pm 0.8$ & 0.285 \\
\hline Amount of injected cement $(\mathrm{mL})$ & $5.4 \pm 1.6$ & $5.0 \pm 1.6$ & $5.1 \pm 1.6$ & 0.232 \\
\hline Cement leakage (yes/no) & $15 / 11$ & $81 / 118$ & $96 / 129$ & 0.100 \\
\hline Fracture level (thoracic/thoracolumbar/lumbar) & $2 / 19 / 5$ & $44 / 121 / 34$ & $46 / 140 / 39$ & 0.228 \\
\hline Fracture age (months) & $1.7 \pm 0.6$ & $1.8 \pm 0.7$ & $1.8 \pm 0.7$ & 0.825 \\
\hline Fracture severity grade (mile/moderate/severe) & $14 / 11 / 1$ & $99 / 65 / 35$ & $113 / 76 / 36$ & 0.350 \\
\hline Location of the fractured area (superior/middle/inferior) & $18 / 6 / 2$ & $84 / 70 / 45$ & $102 / 76 / 47$ & $0.028^{*}$ \\
\hline Preoperative VAS & $7.6 \pm 0.6$ & $7.5 \pm 0.8$ & $7.5 \pm 0.8$ & 0.525 \\
\hline Immediate postoperative VAS & $4.6 \pm 0.7$ & $2.1 \pm 0.9$ & $2.4 \pm 1.2$ & $<0.001^{*}$ \\
\hline
\end{tabular}

${ }^{*}$ Statistically significant

Table 2. Results of multivariate stepwise logistic regression analysis for occurrence of insufficient cement distribution in the fractured area.

\begin{tabular}{|l|c|c|c|}
\hline & OR & 95\%CI & P value \\
\hline Location of the fractured area & & & $0.040^{*}$ \\
\hline Middle versus inferior & 1.9 & $0.4-10.0$ & 0.433 \\
\hline Superior versus inferior & 4.8 & $1.1-21.7$ & $0.041^{*}$ \\
\hline
\end{tabular}

${ }^{*}$ Statistically significant

differences could be found between patients with the fractured area being in the inferior portion and those with the fractured area located in the middle portion $(P$ $=0.433$ ) (Table 2).

\section{Discussion}

Use of PVP as an alternative treatment for some OVCFs refractory to conservative management is controversial, primarily due to 2 previous independent level 1 trials, both of which found that patients randomized to PVP did not experience decreased pain or disability relative to patients in the placebo arm $(17,18)$. Furthermore, although these 2 studies have been criticized for a variety of reasons, the American Academy of Orthopedic Surgeons believed that these 2 studies did have sufficient power to detect the minimal clinically important difference in pain, and clinical practice guideline issued by the American Academy of Orthopedic Surgeons strongly recommended against PVP for symptomatic OVCFs (19). Despite these controversies, increased use of PVP for managing OVCFs has been the trend, likely owing to individual physician experience on the efficacy of PVP, some guidelines recommending PVP $(7,11)$, as well as numerous and ever-increasing research studies showing its benefits (20-24).

To the best of our knowledge, this is the first study conducted to identify the risk factors for the occurrence of ICD following PVP in patients with OVCFs. In addition to osteoporosis as fracture etiology, we restricted the analysis to patients with a single-level fracture and typical location of the fractured area for creating a uniform cohort and simplifying interpretation of the results. Our current study found that the location of the fractured area was revealed to be an independent risk factor for predicting the emergence of ICD. To be specific, ICD was inclined to happen in patients with the fractured area located in the superior portion of the index vertebra. Additionally, patients with ICD were found to experience a lower degree of back pain relief compared with those with sufficient cement distribution in the fractured area.

Stabilization of the fractured area and restora- 
tion of vertebral strength are the most acceptable mechanisms for pain relief after PVP in treatment of OVCFs for the reason that back pain caused by OVCFs is mostly likely to be related to periosteal nerves aggravated by micromotion at the fractured area (25). This hypothesis has been supported by biomechanical studies, which indicated that PVP generally restored or increased vertebral strength and stiffness relative to pre-fracture values and likely provided stabilization of the vertebral body so as to prevent micromotion of the fractured area (26-28). In our present study, based on cement distribution in the fractured area observed in postoperative CT scan, the cohort was categorized into Sufficient Group, consisting of those with sufficient cement distribution in the fractured area, and Insufficient Group, composed of those with ICD, and a higher degree of pain relief was found in the Sufficient Group than in the Insufficient Group. Additionally, incidence of sufficient cement distribution in the fractured area was found to be as high as $88.4 \%$, which was similar to the reported success rate of $89 \%-93 \%$ in PVP for OVCFs (7). These findings, to some extent, support the biomechanical results for explanation of mechanisms of pain relief after PVP for OVCFs from a clinical aspect, which is consistent with studies conducted by $\mathrm{He}$ et al (12), Yang et al (13), and Chui et al (14). Despite unsatisfactory results in the Insufficient Group, patients in this group still experienced some degree of pain relief, which might be explained by partial restoration of vertebral stiffness and strength or thermal $(29,30)$, chemical $(31)$, or placebo effects $(17,18)$.

If the increased stiffness yields stabilization of micromotion in the fractured area, the most important factor for pain reduction is advocated to be the spatial distribution in the fractured area and amount of injected cement is believed to be the second influencing factor (32). Therefore, location of the fractured area and amount of injected cement were considered in our present study. Fracture level and fracture severity grade were also included to eliminate the effect of variants in the size of vertebral bodies on the amount of injected cement caused by these 2 factors. Both univariate and multivariate analyses showed no significant relationship between the amount of injected cement, fracture level, fracture severity grade, and occurrence of ICD, which is in agreement with perspective held by He et al (12). However, significant association of location of the fractured area with occurrence of ICD was found and ICD tended to happen in patients with the fractured area located in the superior portion of the index vertebra. In our view, this is mainly due to Jensen et al's technique (15) we adopted in performing PVP, in which the needle advances routinely towards anterior inferior part of the index vertebra and cement is relatively difficult to diffuse into the fractured area located in the superior part that is comparatively far away from the needle placement when the recommended amount of cement is injected.

Cement leakage has been referred as a possible risk factor of ICD considering that it might hinder injecting the planned amount of bone cement (14). In fact, this speculation is reasonable because some operators argued that injection of bone cement should be terminated as soon as any cement leakage was noted (33). However, a significant relationship between cement leakage and occurrence of ICD could not be detected in our study, although the incidence of cement leakage was higher in the Insufficient Group than in the Sufficient Group. The reason we speculate is that cement injection was temporarily halted when initial cement leakage without any discomfort to the patients was noted and terminated on recurrence of cement leakage in our cases. Furthermore, a certain amount of cement could be considered to be injected in the contralateral side. Obviously, compared with immediate termination on initial cement leakage, the operations we performed should decrease the incidence of ICD.

\section{Limitations}

Firstly, we could not quantitatively and accurately locate the fractured area because almost all the fractured areas were irregular, although we have excluded cases with unclear MRI and extremely irregular fractured areas that involved 2 or 3 parts of the index vertebra. Secondly, definition of sufficient/insufficient cement distribution in the fractured area was only based on observations on postoperative CT instead of accurate measurements as we think measurements of the irregular shape of cement distribution might be impossible. The above factors might have effects on our results, which could not be cancelled out in this study. Furthermore, some other influencing factors that are not taken into consideration in this study might exist. Even so, we believe that a significant association of the occurrence of ICD with the location of the fractured area does exist. In addition, although we consider that the difference in immediate postoperative VAS for back pain could be attributed to cement distribution in the fractured area, there are other variables that could confound the results, such as degree of kyphosis cor- 
rection, thoracolumbar fascia injury, fracture morphology, etc. It would be desirable that would be further studies on the influencing factors of pain relief after PVP for OVCFs by multivariate analysis to eliminate the confounding variables.

\section{Conclusion}

Location of the fractured area is an independent risk factor for the occurrence of ICD and patients with the fractured area located in the superior portion of the index vertebra have a higher incidence of ICD after
PVP for OVCFs. Age, gender, BMD T-score, amount of injected cement, cement leakage, fracture level, fracture age, and fracture severity grade do not increase the risk of occurrence of ICD. In addition, ICD might be responsible for the unrelieved pain after PVP for OVCFs. We should pay attention to cement distribution in the fractured area and make some modifications of the PVP technique by making needles travel relatively close to the fractured area located in the superior portion of the index vertebra when performing PVP for OVCFs.

\section{References}

1. Johnell O, Kanis JA. An estimate of the worldwide prevalence and disability associated with osteoporotic fractures. Osteoporos Int 2006; 17:1726-1733.

2. Radvany MG, Murphy KJ, Millward SF, Barr JD, Clark TW, Halin NJ, Kinney TB, Kundu S, Sacks D, Wallace MJ, Cardella JF; Technology Assessment Committee of the Society of Interventional Radiology. Research reporting standards for percutaneous vertebral augmentation. J Vasc Interv Radiol 2009; 20:1279-1286.

3. Zethraeus N, Borgstrom F, Strom O, Kanis JA, Jonsson B. Cost-effectiveness of the treatment and prevention of osteoporosis-a review of the literature and a reference model. Osteoporos Int 2007; 18:9-23.

4. Borgstrom F, Sobocki P, Strom O, Jonsson $B$. The societal burden of osteoporosis in Sweden. Bone 2007; 40:1602-1609.

5. Rousing R, Hansen KL, Andersen MO, Jespersen SM, Thomsen K, Lauritsen JM. Twelve-months follow-up in fortynine patients with acute/semiacute osteoporotic vertebral fractures treated conservatively or with percutaneous vertebroplasty: A clinical randomized study. Spine (Phila Pa 1976) 2010; 35:478-482.

6. Rousing $R$, Andersen $M O$, Jespersen SM, Thomsen K, Lauritsen J. Percutaneous vertebroplasty compared to conservative treatment in patients with painful acute or subacute osteoporotic vertebral fractures: Three-months follow-up in a clinical randomized study. Spine (Phila Pa 1976) 2009; 34:1349-1354.

7. McConnell CT, Jr., Wippold FJ, 2nd, Ray CE, Jr., Weissman BN, Angevine PD, Fries IB, Holly LT, Kapoor BS, Lo- renz JM, Luchs JS, O'Toole JE, Patel ND, Roth C), Rubin DA. ACR appropriateness criteria management of vertebral compression fractures. J Am Coll Radiol 2014; 11:757-763.

8. Suzuki N, Ogikubo O, Hansson T. The course of the acute vertebral body fragility fracture: Its effect on pain, disability and quality of life during 12 months. Eur Spine J 2008; 17:1380-1390.

9. Galibert P, Deramond H, Rosat P, Le Gars D. [Preliminary note on the treatment of vertebral angioma by percutaneous acrylic vertebroplasty]. Neurochirurgie 1987; 33:166-168.

10. Wang H, Sribastav SS, Ye F, Yang C, Wang J, Liu H, Zheng Z. Comparison of percutaneous vertebroplasty and balloon kyphoplasty for the treatment of single level vertebral compression fractures: A meta-analysis of the literature. Pain Physician 2015; 18:209-222.

11. Barr J D, Jensen ME, Hirsch JA, McGraw JK, Barr RM, Brook AL, Meyers PM, Munk PL, Murphy KJ, O'Toole JE, Rasmussen PA, Ryken TC, Sanelli PC, Schwartzberg MS, Seidenwurm D, Tutton SM, Zoarski GH, Kuo MD, Rose SC, Cardella JF; Society of Interventional Radiology, American Association of Neurological Surgeons, Congress of Neurological Surgeons, American College of Radiology, American Society of Neuroradiology, American Society of Spine Radiology, Canadian Interventional Radiology Association, Society of Neurointerventional Surgery. Position statement on percutaneous vertebral augmentation: A consensus statement developed by the Society of Interventional Radiology (SIR),
American Association of Neurological Surgeons (AANS) and the Congress of Neurological Surgeons (CNS), American College of Radiology (ACR), American Society of Neuroradiology (ASNR), American Society of Spine Radiology (ASSR), Canadian Interventional Radiology Association (CIRA), and the Society of Neurolnterventional Surgery (SNIS). J Vasc Interv Radiol 2014; 25:171-181.

12. He SC, Teng GJ, Deng G, Fang W, Guo JH, Zhu GY, Li GZ. Repeat vertebroplasty for unrelieved pain at previously treated vertebral levels with osteoporotic vertebral compression fractures. Spine (Phila Pa 1976) 2008; 33:640-647.

13. Yang SC, Chen WJ, Yu SW, Tu YK, Kao $\mathrm{YH}$, Chung KC. Revision strategies for complications and failure of vertebroplasties. Eur Spine ] 2008; 17:982-988.

14. Chiu YC, Yang SC, Chen HS, Kao YH, Tu YK, Chung KC. Clinical evaluation of repeat percutaneous vertebroplasty for symptomatic cemented vertebrae. J Spinal Disord Tech 2012; 25:E245-E253.

15. Jensen ME, Evans AJ, Mathis JM, Kallmes DF, Cloft HJ, Dion JE. Percutaneous polymethylmethacrylate vertebroplasty in the treatment of osteoporotic vertebral body compression fractures: Technical aspects. AJNR 1997; 18:1897-1904.

16. Genant HK, Wu CY, van Kuijk C, Nevitt MC. Vertebral fracture assessment using a semiquantitative technique. J Bone Miner Res 1993; 8:1137-1148.

17. Buchbinder R, Osborne RH, Ebeling PR, Wark JD, Mitchell P, Wriedt C, Graves S, Staples MP, Murphy B. A randomized trial of vertebroplasty for painful osteoporotic vertebral fractures. $N$ Engl J Med 
2009; 361:557-568.

18. Kallmes DF, Comstock BA, Heagerty PJ, Turner JA, Wilson DJ, Diamond TH, Edwards R, Gray LA, Stout L, Owen S, Hollingworth W, Ghdoke B, AnnesleyWilliams DJ, Ralston SH, Jarvik JG. A randomized trial of vertebroplasty for osteoporotic spinal fractures. N Engl J Med 2009; 361:569-579.

19. McGuire R. AAOS clinical practice guideline: The treatment of symptomatic osteoporotic spinal compression fractures. J Am Acad Orthop Surg 2011; 19:183-184.

20. Brodano GB, Amendola L, Martikos K, Bettuzzi C, Boriani L, Gasbarrini A, Bandiera S, Terzi S, Greggi T, Boriani S. Vertebroplasty: Benefits are more than risks in selected and evidence-based informed patients. A retrospective study of 59 cases. Eur Spine ] 2011; 20:1265-1271.

21. Gerling MC, Eubanks JD, Patel R, Whang PG, Bohlman HH, Ahn NU. Cement augmentation of refractory osteoporotic vertebral compression fractures: Survivorship analysis. Spine (Phila $\mathrm{Pa}$ 1976) 2011; 36:E1266-E1269.

22. Kotwica Z, Saracen A. Early and longterm outcomes of vertebroplasty for single osteoporotic fractures. Neurol Neurochir Pol 2011; 45:431-435.
23. Sun G, Jin P, Li M, Liu XW, Li FD. Height restoration and wedge angle correction effects of percutaneous vertebroplasty: Association with intraosseous clefts. Eur Radiol 2011; 21:2597-2603.

24. Tanigawa N, Kariya S, Komemushi A, Nakatani M, Yagi R, Sawada S. Added value of percutaneous vertebroplasty: Effects on respiratory function. AJR 2012; 198: $W_{51}-W_{54}$

25. Nieuwenhuijse MJ, Bollen L, van Erkel AR, Dijkstra PD. Optimal intravertebral cement volume in percutaneous vertebroplasty for painful osteoporotic vertebral compression fractures. Spine (Phila Pa 1976) 2012; 37:1747-1755.

26. Martincic D, Brojan M, Kosel F, Stern D, Vrtovec T, Antolic V, Vengust R. Minimum cement volume for vertebroplasty. Int Orthop 2015; 39:727-733.

27. Liang $D$, Ye LQ, Jiang $X B$, Yang $P$, Zhou GQ, Yao ZS, Zhang SC, Yang ZD. Biomechanical effects of cement distribution in the fractured area on osteoporotic vertebral compression fractures: $A$ three-dimensional finite element analysis. J Surg Res 2015; 195:246-256.

28. Chen B, Li Y, Xie D, Yang X, Zheng Z. Comparison of unipedicular and bipedicular kyphoplasty on the stiffness and biomechanical balance of compression fractured vertebrae. Eur Spine J 2011; 20:1272-1280.

29. Leeson MC, Lippitt SB. Thermal aspects of the use of polymethylmethacrylate in large metaphyseal defects in bone. A clinical review and laboratory study. Clin Orthop Relat Res 1993:239-245.

30. Deramond H, Wright NT, Belkoff SM. Temperature elevation caused by bone cement polymerization during vertebroplasty. Bone 1999; 25:17S-21S.

31. Dahl OE, Garvik LJ, Lyberg T. Toxic effects of methylmethacrylate monomer on leukocytes and endothelial cells in vitro. Acta Orthop Scand 1994; 65:147-153.

32. Jin YJ, Yoon SH, Park KW, Chung SK, Kim KJ, Yeom JS, Kim HJ. The volumetric analysis of cement in vertebroplasty: Relationship with clinical outcome and complications. Spine (Phila Pa 1976) 2011; 36:E761-E772.

33. Ren HL, Jiang JM, Chen JT, Wang JX. Risk factors of new symptomatic vertebral compression fractures in osteoporotic patients undergone percutaneous vertebroplasty. Eur Spine J 2015; 24:750-758. 